\title{
Zeowine: The synergy of zeolite and compost. Effects on the physiology of the vine and on the quality of the grapes
} \author{
and Giovan Battista Mattii ${ }^{1}$ \\ ${ }^{1}$ DAGRI, Università degli Studi di Firenze, Viale delle Idee 30, 50019 Sesto Fiorentino (FI) Italy \\ ${ }^{2}$ DN360 Piazza d'Ancona, 3, 56127 Pisa (PI) Italy \\ ${ }^{3}$ CNR, IRET, Via Moruzzi, 1, 56124 Pisa (PI) Italy \\ ${ }^{4}$ Tenuta di Poggio S.S. Società Agricola, Via Poggio al Pino, 16, 56028 San Miniato (PI) Italy
}

Eleonora Cataldo ${ }^{1, *}$, Linda Salvi ${ }^{1}$, Sofia Sbraci ${ }^{1}$, Davide Manzi ${ }^{2}$, Grazia Masciandaro ${ }^{3}$, Cosimo Maria Masini ${ }^{4}$,

\begin{abstract}
The trial aims to improve the protection and management of the soil, the well-being of the plant and the quality of production in the wine supply chain organic and biodynamic, using an innovative product "ZEOWINE" resulting from the composting of waste of the wine and zeolite supply chain. At present, the use of zeolites in agriculture is a fast-spreading practice; their application to soils (both as natural zeolites and in combination with organic and mineral fertilizers) not only increases production but also leads to the exaltation of quality indices. The research was conducted in the 2019 season in San Miniato (Tuscany) on the vineyard of Sangiovese in production, performing the following inter-row treatments at the beginning of January: commercial organic fertilizer, zeolite (clinopthylolite) and zeowine (combination zeolite and compost obtained through grape processing waste) in the respective doses of $20 \mathrm{t} / \mathrm{ha}, 10 \mathrm{t} / \mathrm{ha}$ and $30 \mathrm{t} / \mathrm{ha}$. Following the treatment, we measured gas exchanges and water potential, berry weight, ${ }^{\circ} \mathrm{Brix}, \mathrm{pH}$, acidity, total and extractable anthocyanins and polyphenols. Treatments with Zeowine and zeolites reduced water stress. In Zeowine treatment, soluble solids were lower, while acidity, $\mathrm{pH}$ and berry weight do not vary from control. Statistical differences are also noted in the concentrations of anthocyanins and polyphenols. Results suggest a positive impact of Zeowine treatment on physiology and quality characteristics in V. vinifera.
\end{abstract}

\section{Introduction}

The benefits of the contribution made by compost used as soil improver intended for the cultivation of herbaceous crops [1], in fruit growing, and viticulture [2-3] are now established. A good organic matter content allows to ensure better cultivation conditions for the effects on workability, water retention, soil density, porosity, and permeability and on fixation and slow release of nutrients [4]. On the other hand, water is a fundamental factor for the plants' development; according to its availability in the soil, significant variation of the vegetative development of the grapevine and the composition of the fruits can be obtained [5].

In fact, particular attention was paid to study the increase in temperatures (in particular in the summer) and the increase in the inconstancy of meteoric events; in recent years, in temperate climates, such as the Mediterranean, we are witnessing the progressive occurrence of anomalous seasons, both due to excesses and/or rainfall deficiencies and for abnormal thermal trends in the summer and winter periods [6].

Water stress occurs when water becomes a limiting factor and creates alterations at the morphological, physiological and biochemical levels [7].
Zeolites are alumino-silicates with an open threedimensional tetrahedral framework where there are extraframework cations and water molecules, endowed with high mobility, determining their characteristic properties of ion exchange and reversible dehydration [8]. The crystal structure of a zeolite is, therefore, distinguishable in two portions: the tetrahedral structure (framework) and the contents of the cavities (extraframework). From the physical point of view, the two portions can be considered almost independent, given the mobility of the latter. Differently, from the crystal-chemical point of view they constitute a complex system with inter-relationships and connected properties [9]. Zeolites are characterized by unique physico-chemical properties: high absorption capacity at cation exchange, ionic selectivity, molecular sieve, catalytic activity and high thermal stability up to $750{ }^{\circ} \mathrm{C}$ [10-12].

Recently, in the hilly wine-growing areas characterized by poor water availability and dry summers, qualitative impoverishment of productions due to the interactions between climate change and canopy management techniques were found. Nowadays, the use of zeolites in agriculture is a rapidly spreading practice; their application to soils (both as natural zeolites and in combination with organic and mineral fertilizers) not only

\footnotetext{
* Corresponding author: eleonora.cataldo@unifi.it
} 
increases productivity but also leads to the exaltation of quality indices.

The main objective of this study was to evaluate the effect of 3 treatments on the soil: commercial organic fertilizer, zeolite (clinoptilolite), and zeowine (combination zeolite and compost obtained through grape processing waste, pomace, and stalks) on the physiology and production of Sangiovese grapes. In a first step, the effect on the physiological parameters of the vines was measured. Subsequently, the impact on the yield and on the parameters of the technological and phenolic maturity of the grapes was evaluated.

\section{Materials and methods}

The wine-growing area of the experiment is located in the municipality of San Miniato in the Pisa province (Tuscany, Italy); at the Cosimo Maria Masini Biodynamic Company, owned by the Masini family since 2000, extends over a single hill, 40 hectares planted with vineyards, olive trees, and arable land.

The climate is characterized by hot summers and mild winters. The average annual maximum temperature is about $19{ }^{\circ} \mathrm{C}$, the coldest period is from December to January, instead, the hottest month is August with a maximum temperature of $30{ }^{\circ} \mathrm{C}$. The average annual rainfall is about $800 \mathrm{~mm}$.

The vineyards, located about 100 meters above sea level, extend for about 13 hectares on clay soil, of Pliocene origin, rich in fossils with microclimatic conditions ideal for the vine. The vineyard in which the experiment was carried out was planted in 2010 with Sangiovese grafted on 110R, rows direction to East-West, with a planting of $2.00 \times 0.75$, using a vertical-shootpositioned Guyot training system. The vineyard is characterized by biodynamic management: biodynamic preparations and natural feeding of plants.

Three different treatments were applied to the interrows with the aid of spreaders (period January 2019) of which 5 repetitions each according to the randomized block scheme as described below:

- ZEOWINE (ZW), combination zeolite and farm compost obtained from grape processing waste, pomace, and stalks in dose $30 \mathrm{t} / \mathrm{ha}$;

- Natural Zeolite (Z), clinoptilolite in dose $10 \mathrm{t} / \mathrm{ha}$;

- Compost (CTRL), organic fertilizer in dose $20 \mathrm{t} / \mathrm{ha}$.

We proceed with the aim of applying, for the first time, on a new vineyard plant in production, the Zeowine product, with further effects in terms of performance in soil management and soil and plant biodiversity. Zeowine was created by combining the properties of zeolite, whose use in the recovery of contaminated and degraded soils and environments has excellent potential in many sectors as well as in agriculture, with the stable organic substance of a compost obtained on a company scale from the reuse of processing waste of grapes, pomace and stalks.

The infrared gas analyzer, CIRAS 3 (PP Systems Amesbury, MA USA), was used to detect gas exchanges on single-leaf gaseous exchanges.
The stem water potential of the plant was measured with the Scholander pressure chamber PMS 600 EXP and expressed in MPa.

The technological analyses concerned the determination of the soluble solids with optical refractometer, the $\mathrm{pH}$ and the total acidity of the must; while the analyses for the determination of anthocyanins and polyphenols were carried out by the Glorie method.

The collected data was subjected to analysis of the variance and mean separation through the LSD test with SPSS Data Editor. LSD value was reported in the graphs with vertical bars.

\section{Results and discussion}

The treatments under comparison differently affected gas exchanges: compost (ctrl) reported a significant increase in net photosynthesis (Fig. 1); while there were no differences in transpiration and stomatal conductance between treatments.

The values of stomatal conductance (gs) never fell below the stress threshold of $100 \mathrm{mmol} / \mathrm{m}^{2} \mathrm{~s}$ in any of the treatments, revealing conditions of no stress.

There was a reduction in leaf temperature in the Zeowine treated during the warmer period (Fig. 2).

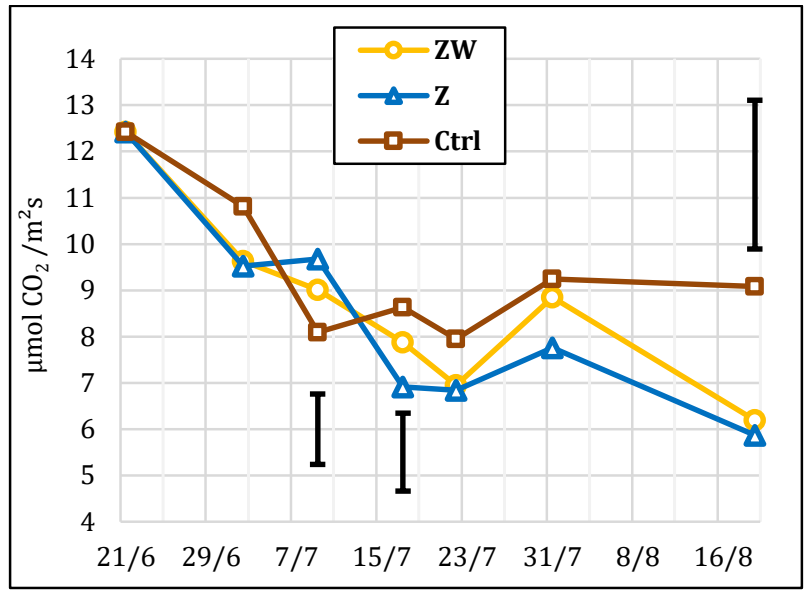

Fig. 1. Seasonal trend of net photosynthesis.

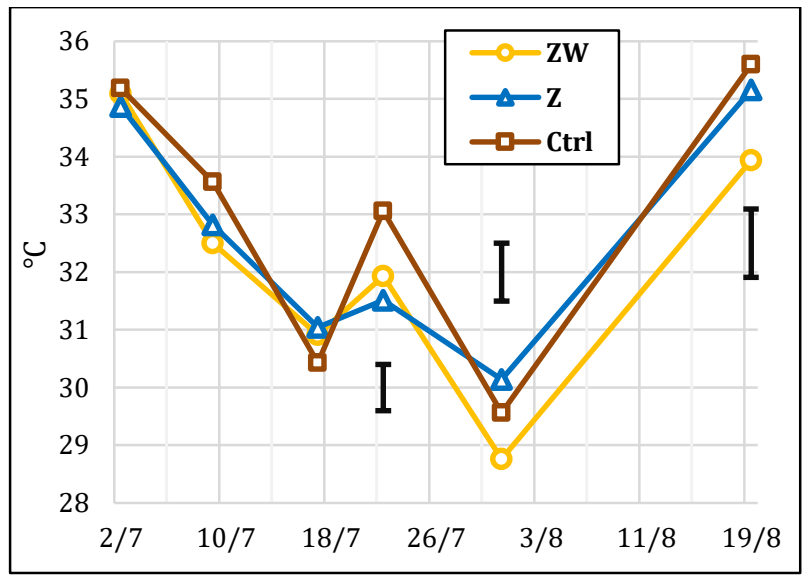

Fig. 2. Seasonal trend of leaf temperature.

$\mathrm{Z}$ and ZW treamtents showed slightly lower values of midday stem water potential; we can therefore appreciate 
the benefit of the treatments during the warmer period already after six months from the application. (Fig. 3).

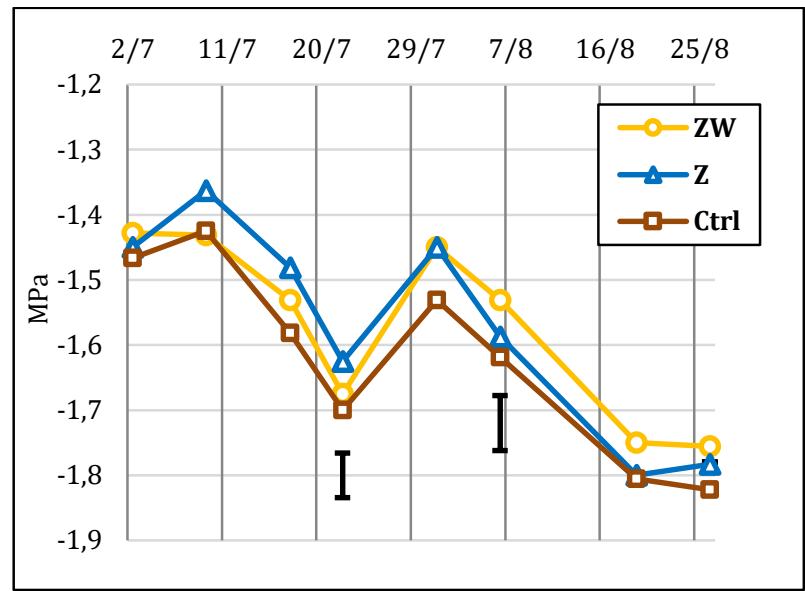

Fig. 3. Seasonal trend of midday stem water potential.

As far as technological analysis is concerned, there was a greater Brix accumulation in the control treatment (Fig. 4); the lower water potential determined a greater dehydration of the berry leading to soluble solids accumulation by concentration.

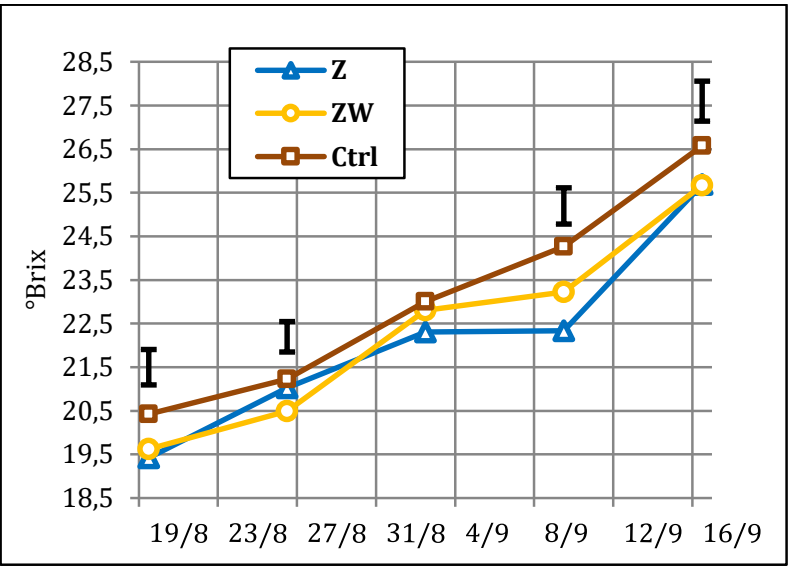

Fig. 4. Seasonal trend of soluble solids content.

A lack significant differences was ascertained as regards the phenolic concentration at harvest, since the different treatments maintained the quality level of the standard grapes (Fig. 5, 6). However, it could be noted an advance of maturation with regard to the treatment with only commercial compost; extractable anthocyanins reached their peak around September $2^{\text {th }}$ and then suffered a physiological decrease (Fig. 5).

In the production data there was a greater production per plant in the zeolite with a higher plant number of clusters probably attributable to the upper aqueous component (data not reported). The lower concentration of soluble solids in $\mathrm{Z}$ and $\mathrm{ZW}$ treatments could be due to the greater yield in Zeolite treatments.

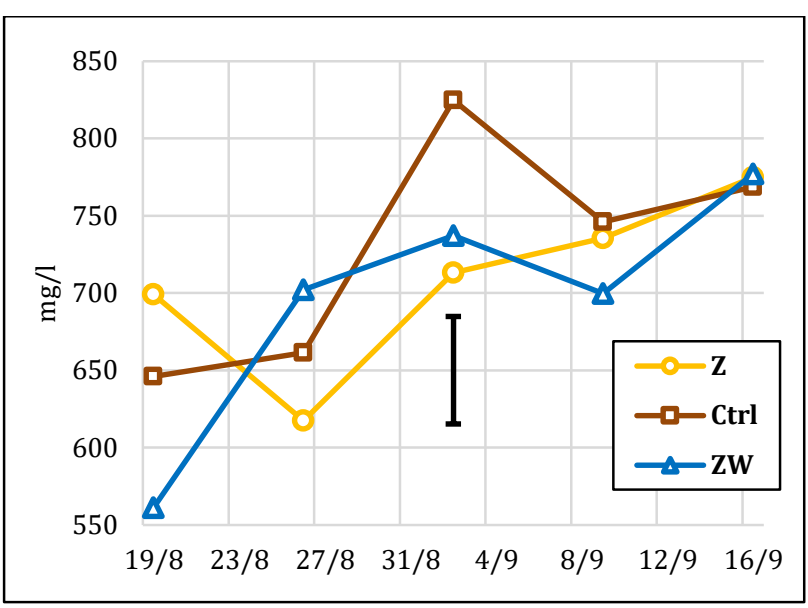

Fig. 5. Seasonal trend of extractable anthocyanins concentration.

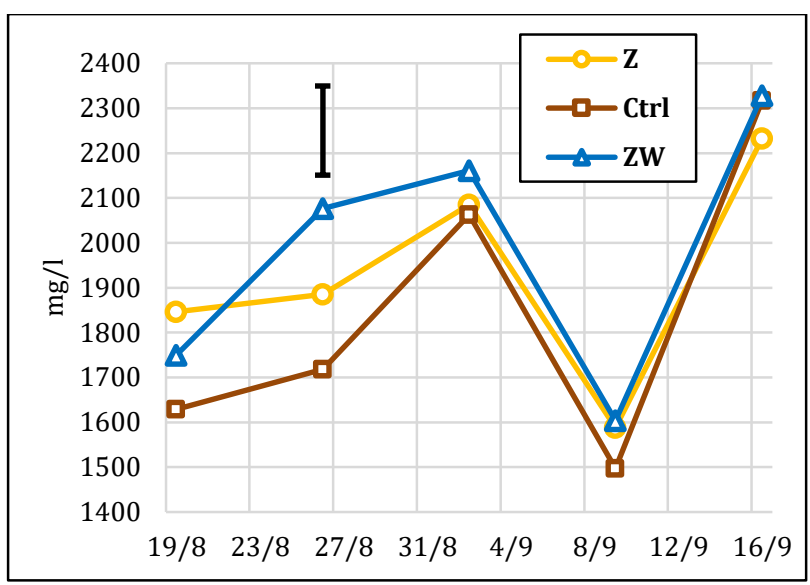

Fig. 6. Seasonal trend of extractable polyphenols concentration.

\section{Conclusion}

One of the main advantages of zeolites is their ability to hydrate and rehydrate which can have a significant impact on maintaining a proper water balance in the soil and to prevent the drying of soil-like soils and substrates. Due to the high porosity, zeolite can store large amounts of water. This is especially important during water deficit events [13].

Of fundamental economic and environmental importance is the fact that once introduced into the soil the zeolites are an integral and indestructible part of it and are therefore forever in the possibility of carrying out their specific positive effects with consequent considerable environmental benefits (reduction of nitrate pollution of the hydrological system and the accumulation of salts in the soil) and economic (increase in quality and quantity of production; savings in the use of water and fertilisers) [14].

In order to reduce the phenomena of phase shift between technological and phenolic maturity attributable to the interactions between the ongoing climate changes and the changed vineyard management techniques, the application of zeolites and Zeowine can represent a valid agronomic practice to assist winemakers. 
The reduction of the sugar content and the unaltered anthocyanic and polyphenolic kit lead to the construction of more balanced wines.

The water availability of a vineyard is a fundamental element for the vegetative and fruit growth and for the physiological and biochemical mechanisms. The quality of the harvest and the evolution of the berry (sugars, total acidity, $\mathrm{pH}$, phenolic compounds) are decisive for the style of wine.

The synergy of the positive effects of Zeowine on the soil and on the plant is demonstrated by the improvement of water efficiency, by the possible future reduction of fertilizer intake, by the closure of the production cycle of the waste material of the supply chain and by the quality of the wine produced.

\section{References}

1. C. Maucieri, A. Barco, M. Borin. Agronomy, 9 (2019).

2. P. Flavio, and L. Sicher. "Compost utilization in fruit production systems." In Compost utilization in horticultural cropping systems. New York, USA: Lewis Publishers (2001).

3. R. de Oliveira Galvão, S.E. de Araújo Neto, N.M. da Silva, L.G. de Souza, T.L. Uchôa, R.L.F. Ferreira. Comunicata Scientiae, 11, e3398 (2020).

4. M.C. Ramos. Agric Water Manag, 191, 67-76 (2017).

5. C.P. Des Gachons, C. Van Leeuwen, T. Tominaga, J.P. Soyer, J.P. Gaudillère, D. Dubourdieu. J. Sci. Food Agric., 85, 73-85 (2005).

6. S. Tombesi, P, Stefano, and A. Palliotti. Italus Hortus, 23, 45-53 (2016).

7. E. Cataldo, L. Salvi, G.B. Mattii. Plant Physiol. Biochem., 164, 247-259 (2021).

8. K. Ramesh, D.D. Reddy. Adv. Agron., 113, 219241 (2011).

9. C. Sangeetha, P. Baskar. Agric. rev., 37, 101-108 (2016).

10. J.A. Al-Tabbal, N.K. Al-Mefleh, K.K. AlZboon, M.J. Tadros. Environ. Nat. Resour. J., 18, 44-54 (2020).

11. S.K. Pitcher, R.C.T. Slade, N.I. Ward. Sci. Total Environ. 334, 161-166 (2004).

12. Y.T. Tran, J. Lee, P. Kumar, K.H. Kim, S.S. Lee. Composites Part B: Engineering, 165, 354-364 (2019).

13. M. Ghanbari, A. Siavash. Int. J. Med. Arom. Plants, 3, 32-39 (2013).

14. E. Passaglia, D. Prisa. Contributo delle zeolititi nella mitigazione delle problematiche ambientali conseguenti alle vigenti pratiche agricole (Lulu Press, 2018). 